Hahn, T. J., Hendin, B. A., Scharp, C. R., and Haddad, J. G., jun., (1972). New England fournal of Medicine. In press.

Holick, M. F., Schnoes, H. K., and DeLuca, H. F. (1971). Proceedings of the National Academy of Sciences, 68, 803 .

Kodicek, E., Lawson, D. E. M., and Wilson, P. W. (1970). Nature, 228, 763.

Kruse, R. (1968). Monatsschrift fürKinderheilkunde, 116, 378.
Lawson, D. E. M., Fraser, D. R., Kodicek, E., Morris, H. R., and Williams, D. H. (1971). Nature, 230, 228

Pak, C. Y. C., et al. (1970). Archives of Internal Medicine, 126, 239.

Reifenstein, E. C., jun., Albright, F., and Wells, S. L. (1945). Fournal of Clinical Endocrinology, 5, 367.

Richens, A., and Rowe, D. J. F. (1970). British Medical fournal, 4, 73.

\title{
Therapeutic Abortion by Intra-amniotic Injection of Prostaglandins
}

\author{
G. ROBERTS, R. GOMERSALL, M. ADAMS, A. C. TURNBULL
}

British Medical fournal, 1972, 4, 12-14

\section{Summary}

Intra-amniotic injection of either prostaglandin $\mathbf{F}_{2} \alpha$ or prostaglandin $E_{2}$ was used in an attempt to induce therapeutic abortion in mid-pregnancy in 27 patients. Termination of pregnancy was successful in 11 out of 13 cases when prostaglandin $E_{2}$ alone was used, but in only 6 out of 14 cases when prostaglandin $F_{2} \alpha$ was used. $A$ further eight patients aborted after additional intravenous oxytocin stimulation, but the combined procedures failed altogether in two patients who were initially given prostaglandin $\mathbf{F}_{2} \alpha$. The technique was simple, free from serious side effects, and reasonably effective when prostaglandin $E_{2}$ was used.

\section{Introduction}

The abortificient properties of prostaglandins have been publicized wideiy in both the medical and the lay press because they have been reported to be successful (Karim and Filshie, 1970, 1972) as well as safe. The existence of such an effective medical method for terminating pregnancy would argue against the continued use of surgical techniques, with their disadvantages of trauma, haemorrhage, and secondary infection. Other workers, however, have not been able entirely to confirm these reports of the efficacy of prostaglandins for termination in either early or mid-pregnancy (Wiqvist and Bygdeman, 1970; Roberts et al., 1971). Further trials are urgently needed to establish the best role for these potent drugs in clinical practice.

The intravenous administration of prostaglandins has been most extensively investigated to date. Although generally successful, its disadvantages are that it causes nausea, vomiting, and phlebitis and that in some cases the induction-abortion interval is prolonged. In an attempt to minimize or even eliminate systemic side effects other routes of administration have been tried, including transcervical extra-amniotic injection (Wiqvist and Bygdeman, 1970; Embrey and Hillier, 1971; Roberts et al., 1971). Recently the successful use of a single transabdominal intra-amniotic injection of prostaglandins for the induction of mid-pregnancy abortion was reported by Karim and Sharma (1971). The results of a similar trial in Cardiff are now presented, including some data obtained by recording myometrial contractility. Plasma oestrogens and progesterone were also measured in some of these patients and the results will be published in a separate report (Symonds et al., 1972).

\footnotetext{
Department of Obstetrics and Gynaecology, University Hospital of Wales, Cardiff Maternity Hospital, Cardif

G. ROBERTS, M.B., M.R.C.o.G., Senior Registrar

R. GOMERSALL, M.B., M.R.C.O.G., Registrar

M. ADAMS, M.B., B.CH., Senior House Officer

A. C. TURNBULL, M.D., F.R.C.o.G., Professor
}

\section{Patients and Methods}

The study was performed on 27 patients with pregnancies of between 14 and 22 weeks' gestation. Each patient was sedated with $10 \mathrm{mg}$ of morphine and $5 \mathrm{mg}$ of perphenazine by intramuscular injection given about one hour before the procedure. Transabdominal amniocentesis with an 11-gauge needle was performed under local anaesthesia ( $1 \%$ lignocaine). A polyethylene cannula was inserted through the needle into the amniotic cavity and the needle withdrawn over it. Uterine activity was monitored when possible by connecting the cannula to a Devices pressure transducer and recorder. Basal uterine activity was recorded for 30 minutes before administration of the prostaglandins. Prostaglandin $\mathrm{F}_{2} \alpha$ was given as a single intra-amniotic injection of $25 \mathrm{mg}(5 \mathrm{mg} / \mathrm{ml})$ in the first 14 cases, except for one patient (Case 10) who was given three such doses at intervals of 24 hours for three successive days. Prostaglandin $E_{2}$ was used in the next 13 cases, a different regimen being followed (by request of the manufacturers). This consisted of an initial injection of $1 \mathrm{mg}(1 \mathrm{mg} / \mathrm{ml})$ followed by two further $1-\mathrm{mg}$ doses at 10 -minute intervals. Because uterine activity diminished in some patients (Cases 18, 21, 23, 25 , and 26) further 3-mg intra-amniotic injections were given (see Table II). In all patients pulse rate, blood pressure, and body temperature were recorded every four hours and analgesic drugs were prescribed when required. Intravenous oxytocin infusions were used when pregnancy could not be terminated with prostaglandins alone. Hysterotomy was performed only when all the "medical" methods had failed.

A complete record of amniotic fluid pressure changes was obtained from only two patients (Cases 1 and 5). Transient blockage of the cannula was common so that many tracings were intermittent, and in other cases monitoring was discontinued on ethical grounds because induction of abortion was proving so prolonged.

\section{Results}

A single intra-amniotic injection of $25 \mathrm{mg}$ of prostaglandin $\mathrm{F}_{2} \alpha$ successfully terminated pregnancy in only six out of 14 cases, the average induction-delivery interval being 19 hours 31 minutes (Table I). In a further six patients cervical dilation had reached $2 \mathrm{~cm}$ after intervals varying from 24 to 48 hours, and intravenous oxytocin infusions were then required to stimulate effective uterine activity. In this group the average induction-abortion interval was 59 hours, being particularly prolonged in primigravidae. Two patients (Cases 6 and 14) failed to abort at all. The cervix remained tightly closed despite further attempts to augment uterine activity by injecting hypertonic saline into the amniotic sac and giving additional intravenous infusions of oxytocin. Hysterotomy had to be performed in both these cases. Abortion was incomplete in seven of the 12 patients who were delivered vaginally.

In patients given prostaglandin $\mathrm{E}_{2}$ the success rate was much 
TABLE I-Therapeutic Abortion Induced by 25-mg Dose of Transabdominal Intra-amniotic Prostaglandin $F_{2} \alpha$

\begin{tabular}{|c|c|c|c|c|c|}
\hline $\begin{array}{l}\text { Case } \\
\text { No. }\end{array}$ & Age & Gravida & $\begin{array}{c}\text { Gestation } \\
\text { Period } \\
\text { (Weeks) }\end{array}$ & $\begin{array}{c}\text { Induction- } \\
\text { Abortion } \\
\text { Interval } \\
\text { (hr/min) }\end{array}$ & $\begin{array}{l}\text { Complete } \\
\text { or } \\
\text { Incomplete }\end{array}$ \\
\hline $\begin{array}{r}1 \\
2 \\
3 \\
4 \\
5 \\
6 \\
7 \\
8 \\
9 \\
10 \\
11 \\
12 \\
13 \\
14\end{array}$ & $\begin{array}{l}37 \\
16 \\
26 \\
35 \\
25 \\
24 \\
36 \\
40 \\
15 \\
17 \\
21 \\
20 \\
23 \\
18\end{array}$ & $\begin{array}{l}3 \\
1 \\
2 \\
7 \\
4 \\
1 \\
3 \\
5 \\
1 \\
1 \\
4 \\
2 \\
4 \\
1\end{array}$ & $\begin{array}{l}16 \\
19 \\
19 \\
17 \\
16 \\
22 \\
14 \\
18 \\
17 \\
16 \\
17 \\
17 \\
16 \\
16\end{array}$ & $\begin{array}{c}15 \cdot 40 \\
75 * \\
35 \cdot 15 \\
17 \cdot 25 \\
5 \cdot 30 \\
\text { Failed* } \\
19 \cdot 00 \\
25 \cdot 00 \\
27 \cdot 30^{*} \\
150 \cdot 00^{*} \\
29 \cdot 10^{*} \\
50 \cdot 00^{*} \\
22 \cdot 30^{*} \\
\text { Failed* }\end{array}$ & $\begin{array}{l}\text { Complete } \\
\text { Complete } \\
\text { Incomplete } \\
\text { Incomplete } \\
\text { Complete } \\
\text { Incomplete } \\
\text { Incomplete } \\
\text { Incomplete } \\
\text { Incomplete } \\
\text { Incomplete } \\
\text { Complete } \\
\text { Complete }\end{array}$ \\
\hline
\end{tabular}

* Intravenous oxy tocin used as well.

TABLE II-Therapeutic Abortion Induced by Three 1-mg Doses of Transabdominal Intra-amniotic Prostaglandin $E_{2}$ at 10-minute Intervals

\begin{tabular}{c|c|c|c|c|c}
$\begin{array}{c}\text { Case } \\
\text { No. }\end{array}$ & Age & Gravida & $\begin{array}{c}\text { Gestation } \\
\text { Period } \\
\text { (Weeks) }\end{array}$ & $\begin{array}{c}\text { Induction- } \\
\text { Abortion } \\
\text { Interval } \\
\text { (hr/min) }\end{array}$ & $\begin{array}{c}\text { Complete } \\
\text { or } \\
\text { Incomplete }\end{array}$ \\
\hline 15 & 19 & 1 & 15 & $26 *$ & Incomplete \\
16 & 21 & 4 & 16 & $20 \cdot 45$ & Incomplete \\
17 & 15 & 1 & 16 & $9 \cdot 30$ & Complete \\
$18 \dagger$ & 16 & 1 & 16 & 33.20 & Complete \\
19 & 23 & 3 & 14 & $8 \cdot 35$ & Complete \\
20 & 18 & 1 & 16 & 99 & Complete \\
$21 \dagger$ & 20 & 1 & 18 & $28 \cdot 50$ & Complete \\
22 & 19 & 1 & 16 & 11.25 & Complete \\
$23 \ddagger$ & 18 & 1 & 18 & 27.37 & Complete \\
24 & 22 & 2 & 17 & 12 & Incomplete \\
$25 \dagger$ & 17 & 2 & 16 & $34 \cdot 5$ & Incomplete \\
$26 \ddagger$ & 14 & 1 & 22 & $70 \cdot 20^{*}$ & Complete \\
27 & 38 & 10 & 15 & $11 \cdot 50$ & Complete \\
\hline
\end{tabular}

* Intravenous oxytocin used as well.

Further $3 \mathrm{mg}$ prostaglandin $\mathrm{E}_{2}$ at 24 hours.

Case No. 26 had additional $1 \mathrm{mg}$ prostaglandin $E_{2}$ at 24,28 , and 32 hours.

higher, 11 of the 13 patients aborting; the average inductionabortion interval was 18 hours 41 minutes (Table II). Only two patients (Cases 15 and 26) required additional intravenous oxytocin infusions; their average induction-delivery interval was 48 hours in this group. Abortion was incomplete in only four of the 13 cases.

With prostaglandin $F_{2} \alpha$ the primigravid patients had a particularly high failure rate, prolonged induction-delivery times, and a high incidence of incomplete abortion (Tables III and IV). With prostaglandin $E_{2}$, however, the parity of the patient seemed to have little effect on the outcome as there was generally a successful result.

TABLE III-Effect of Parity on Mean Induction-Delivery Interzals (in Hours and Minutes) with Prostaglandin $F_{2} \alpha$

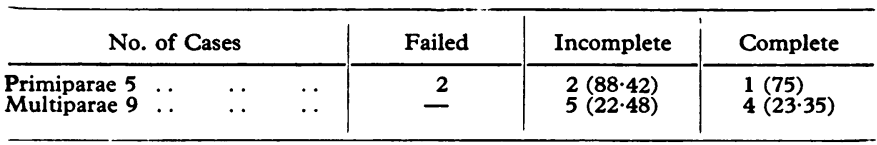

TABLE IV-Effect of Parity on Mean Induction-Delivery Intervals (in Hours and Minutes) with Prostaglandin $E_{2}$

\begin{tabular}{|c|c|c|c|c|c|}
\hline \multicolumn{3}{|c|}{ No. of Cases } & \multirow{2}{*}{$\begin{array}{c}\text { Failed } \\
=\end{array}$} & \multirow{2}{*}{$\begin{array}{c}\text { Incomplete } \\
1(26) \\
3(22 \cdot 15)\end{array}$} & \multirow{2}{*}{$\begin{array}{l}\text { Complete } \\
7(27 \cdot 08) \\
2(10 \cdot 12)\end{array}$} \\
\hline $\begin{array}{ll}\text { Primiparae } & 8 \\
\text { Multiparae } & 5\end{array}$ & . & $\ldots$ & & & \\
\hline
\end{tabular}

\section{SIDE EFFECTS}

Severe abdominal pain was experienced for about 20 minutes by all the patients given prostaglandin $F_{2} \alpha$, occurring either immediately or, more usually, 15 minutes after the injection. With prostaglandin $\mathrm{E}_{2}$ abdominal pain generally started when the second 1-mg dose was administered, 10 minutes after the first dose. The explanation of the severe pain is not clear, but it appears to be associated with the uterine hypertonus which develops after the injection of prostaglandin (Fig. 1). One patient given prostaglandin $F_{2} \propto$ and three patients given prostaglandin $\mathrm{E}_{2}$ vomited. During the induction period most patients were noted to have a mild pyrexia $\left(38 \cdot 0^{\circ} \mathrm{C}\right)$. Blood loss was not excessive and no patient required a blood transfusion.

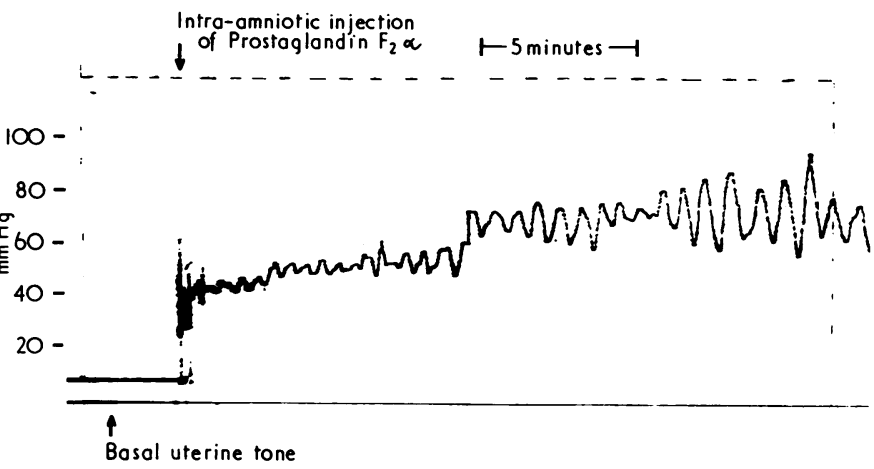

FIG. 1-Intrauterine pressure tracing showing increases in uterine tone after intra-amniotic injection of prostaglandin $F_{2} \alpha$.

\section{UTERINE ACTIVITY}

Before the intra-amniotic injection of prostaglandin, no uterine activity was noted (Fig. 1). Either immediately or, more commonly, 15 minutes after the injection, a burst of uterine activity occurred, characterized by rapidly increasing uterine tone associated with frequent small uterine contractions. In the patients who were both monitored and aborted successfully regular contractions of increasing strength became superimposed on the increased uterine tone (Fig. 2), which persisted up to the time of abortion at a level of between 12 and $50 \mathrm{~mm} \mathrm{Hg}$. In other patients uterine activity waned (Fig. 3) and the contractions disappeared after a varying time interval. In the two cases in which the uterine activity was monitored during the

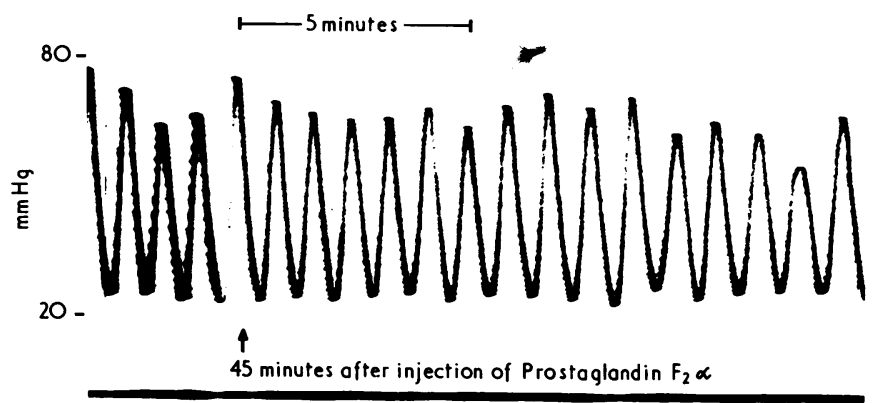

FIG. 2-Intrauterine pressure tracing showing regular uterine contractions induced by intra-amniotic injection of prostaglandin $F_{2} \alpha$.

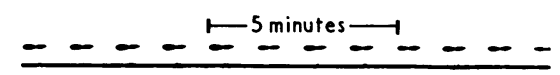

$100-$

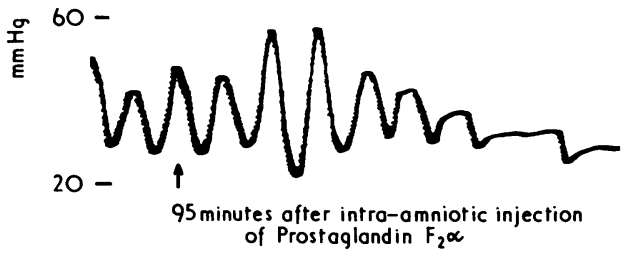

FIG. 3-Intrauterine pressure tracing in unsuccessful case showing waning and disappearance of uterine contractions. 
whole induction-abortion interval (Cases 1 and 5) the entire record was divided into 10 equal phases or time intervals. In each phase, the average strength of contractions (represented by the peak amplitudes above the baseline) was measured in $\mathrm{mm}$ $\mathrm{Hg}$ and the average frequency was recorded as the number of contractions occurring in 10 minutes. Initially, uterine contractions were very frequent and of small amplitude, but as the abortion proceeded the frequency fell and the intensity increased, reaching levels between 88.7 and $110 \mathrm{~mm} \mathrm{Hg}$ (Figs 4 and 5).

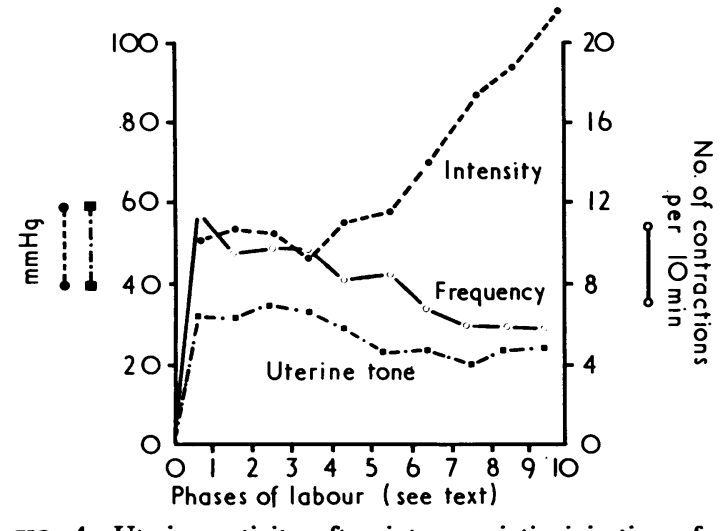

FIG. 4-Uterine activity after intra-amniotic injection of $25 \mathrm{mg}$ of prostaglandin $F_{2} \alpha$ (Case 1).

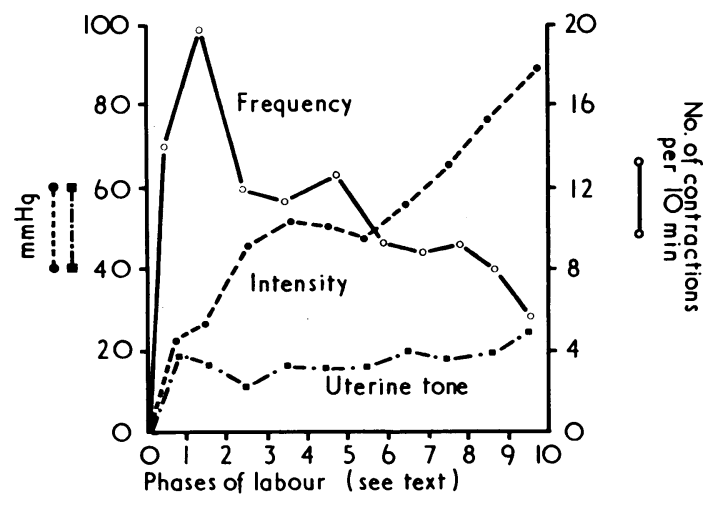

FIG. 5-Uterine activity after intra-amniotic injection of $25 \mathrm{mg}$ of prostaglandin $\mathrm{F}_{2} \alpha$ (Case 5).

\section{Discussion}

The results of this study have been disappointing compared with those reported by Karim and Sharma (1971). In their series of 10 cases (three treated with prostaglandin $F_{2} \alpha$ and seven with prostaglandin $\mathrm{E}_{2}$ ) the injection-abortion interval ranged from $4 \frac{1}{2}$ to 18 (mean 11.4 ) hours. In our study prostaglandin $F_{2} \alpha$ alone was successful in only six out of 14 cases, with an average induction-delivery interval of nearly 20 hours. In a further six cases intravenous oxytocin was used, with a resultant average induction-delivery interval of 59 hours, and in two cases hysterotomy was required. With prostaglandin $\mathrm{E}_{2}$ the results were much better, 11 out of 13 patients $(84 \%)$ being delivered, with an average induction-abortion interval of 18 hours 41 minutes. The total dosage of prostaglandin $E_{2}$ used in most of our cases was $3 \mathrm{mg}$, whereas Karim and Sharma (1971) gave a single injection of $5 \mathrm{mg}$. There was a high incidence of incomplete abortion in both groups, but it was twice as high with prostaglandin $\mathrm{F}_{2} \alpha(60 \%)$ as with prostaglandin $\mathrm{E}_{2}(30 \%)$.

The trends in utcrine activity after intra-amniotic prostaglandin injection, with an initial noticeable increase and then a fall in frequency of contractions coupled with a steady increase in the strength of contractions to very high peak pressures between 88 and $110 \mathrm{~mm} \mathrm{Hg}$, were quite different from those seen in norn.al labour at term. They were, however, very similar to those found during abortion induced by the intra-amniotic injection of hypertonic saline (Turnbull and Anderson, 1965). The similarity between the pattern of uterine contractions induced by the two methods lends support to the idea that the hypertonic saline techniques may act by liberating prostaglandins within the uterus.

Symonds et al. (1972) suggested that prostaglandins injected into the amniotic sac probably cause abortion by a direct effect on the myometrium because they could not find any difference in the trends in plasma oestrogen or progesterone levels between patients who aborted and those who did not. The main difference between the patterns of contractility induced by hypertonic saline and by prostaglandins injected into the amniotic sac is the high resting tone in cases treated with prostaglandins; this may just mean that much more prostaglandin reaches the myometrium in the latter group. In the doses we have used prostaglandins injected into the amniotic sac do appear to cause considerable overstimulation of the uterus, judging by the severe pain experienced by the patients, which seems to be associated with the development of hypertonus.

Intra-amniotic administration of prostaglandins holds the great potential advantage that therapeutic abortion may be induced by a single injection. It was disappointing to find in cases treated with prostaglandin $F_{2} \alpha$, however, that despite high initial uterine activity and the development of strong regular contractions, in over half the cases the gestational sac was not aborted, for the contractions gradually lessened and then ceased. We do not know why uterine activity waned in some cases and not in others. Possibly in the patients who failed to abort tachyphylaxis developed (Embrey and Hillier, 1971), or perhaps the prostaglandins were being rapidly metabolized to inert compounds. If so, synthetic prostaglandin analogues more resistant to metabolic breakdown might prove extremely effective. So far as the action of the prostaglandins available at present is concerned the myometrium may be more responsive to repeated small doses. The much higher success rate with prostaglandin $\mathrm{E}_{2}$ was possibly due in part to the intermittent dosage regimen, although this prostaglandin is a much more potent oxytocic agent than prostaglandin $\mathrm{F}_{2} \alpha$ (Roberts and Turnbull, 1971). The use of larger intra-amniotic doses of either drug is limited by the severe pain caused with this method of administration.

Every method of terminating second-trimester pregnancy has serious disadvantages. Much morbidity could be avoided by speeding up referral and assessment to enable most terminations to be performed safely early in pregnancy, perhaps on an outpatient basis (Lewis et al., 1971). Nevertheless, many patients requiring therapeutic abortion will continue to present in the second trimester, and in our experience so far intra-amniotic injection of prostaglandin $\mathrm{E}_{2}$ may prove to be valuable in such cases. Intra-amniotic injection of prostaglandin $\mathrm{F}_{2} \alpha$ has given disappointing results and we do not propose to continue its use. More work is required to establish the optimum dosage for intra-amniotic administration of prostaglandin $\mathrm{E}_{2}$ and to improve the results with intravenous and extra-amniotic injection of prostaglandin $\mathrm{E}_{2}$ in controlled trials. Prostaglandins seem likely to provide the safest and most effective means of terminating second-trimester pregnancy, but the best method for administering them remains tantalizingly uncertain.

We thank the Upjohn Company for providing the prostaglandins, and the nursing staff of the gynaecological ward at Llandough Hospital for their invaluable help.

\section{References}

Embrey, M. P., and Hillier, K. (1971). British Medical fournal, 1, 588.

Karim, S. M. M., and Filshie, G. M. (1970). British Medical fournal, 3, 198 Karim, S. M. M., and Filshie, G. M. (1972). Fournal of Obstetrics and Gynaecology of the British Commonwealth, 79, 1.

Karim, S. M. M., and Sharma, S. D. (1971). Lancet, 2, 47.

Lewis, S. C., Lal, S., Branch, B., and Beard, R. W. (1971). British Medical fournal, 4,1972

Roberts, G., and Turnbull, A. C. (1971). British Medical fournal, 1, 702.

Roberts, G., Cassie, R., and Turnbull, A. C. (1971). Journal of Obstetrics $\rightleftharpoons$ and Gynaecology of the British Commonwealth, 78, 834

Symonds, E. M., Fahmy, D., Morgan, C., Roberts, G., Gomersall, C. R., and Turnbull, A. C. (1972). In press.

Turnbull, A. C., and Anderson, A. B. M. (1965). Fournal of Obstetrics and Gynaecology of the British Commonwealth, 72, 755

Wiqvist, N., and Bygdeman, M. (1970). Lancet, 2, 716. 